\title{
The Role of Professional Landing Pages in Increasing Conversion Rates by Applying to the Saudi Electronic Marketing Websites
}

\author{
Abeer Elsayed Fayed \\ Faculty of Business Administration \\ University of Tabuk, Tabuk, Saudi Arabia \\ Academy of Specialized Studies \\ Egypt
}

\begin{abstract}
Professional landing pages have a significant role in increasing conversion rates of electronic marketing sites. The study attempted to identify this role and the criteria needed for creating a professional landing page that contributes to increasing conversion rates in the countries recently using electronic marketing such as Arab countries. There is no study addressing the promising Arab markets on the subject of electronic marketing. The study was conducted on the Saudi market; its electronic marketing sites suffer from low turnout. The study concluded that one of the main reasons for this decline is the ineffectiveness of an important tool of electronic marketing in these sites, which is landing pages. They either do not exist in these sites or lack the correct criteria. This study will help the administrators and owners of these sites to take care of this important tool, and how to create them professionally to enhance their electronic marketing sites distinctly.
\end{abstract}

Keywords: Landing pages, conversion rates, electronic marketing, landing page content, landing page marketing message, granting trust for landing pages

\section{Introduction}

The process of persuading and attracting consumers online is very difficult. Therefore, every day new methods, tools, and strategies are developed to deal with electronic marketing. Thus, what was modern yesterday becomes useless today, and other forms are created. Sites always seek to create tools that attract consumers online. Landing page approved to be one of the most successful tools to increase conversion rates. A successful landing page is one of the most important factors in electronic marketing success, through which visitors surf presentation or selling page of a marketed product through the websites.

A landing page is a webpage designed to receive visitors from the advertising campaign on the site's homepage. It also aims to deliver a message to appropriate visitors urging them to take a specific action. When the page is properly directed to the appropriate visitor, the number of conversions increases and the profits generated by electronic marketing consequently increase.

The landing page is a separated page from the site's homepage. It targets visitors to urge them to take a specific action. Therefore, professional pages do not include any things that may distract the visitor from doing the desired action such as having side links, double messages, or advertisements.

Arguing to take a specific action, not through the homepage is not acceptable for a visitor to read the landing page and ask him or her to buy immediately. This method leads to the loss of the visitor, but the ideal method is to convert them to the landing page, whose main purpose is to urge the visitor to take a specific action that is often to buy or even subscribe to mailing lists.

The professional landing page attracts visitors and makes them do the required action. However, if the landing page is inadequate and not attractive to the visitor, he will log out, which considers a direct loss, especially for the sites relying on paid visitors. Thus, the sites give due attention to this tool, which has become essential and significant to increase the conversion rates.

\section{Literature Review:}

Due to the novelty of the topic, no dedicated studies dealt with it. However, the studies dealt with aspects other than the landing page and referred to the landing page through studying it. 
Among these papers, a study, Invernizzi, al et (2016), concluded that landing pages helped convert visitors to customers. Landing pages attract and urge them to take the desired action from the site, which is often to purchase or subscribe to the mailing lists. The study of Jose (2017) indicated that marketing message on the landing page is very significant. The study emphasizes the necessity for compatibility in the marketing message between the advertisement submitted by the site and landing page; there must be no conflict between them. The visitor should expect what they will find when clicking the link of the ad. A landing page should satisfy the visitor as promised in the advertisement, otherwise the site will lose the click that it may have paid.

The study of Wang (2017) agrees with the previous study that the message content promoted by an advertisement is the best method through which sites can get a professional landing page. Therefore, the site's administrators need to develop their writing skills of the advertisement's content, focusing only on what important to the visitors so that the site can attract the visitor to click on the offer and convert.

The study of Salem (2017) indicated that the compatibility of the marketing message is critical and that it is one of the most significant factors of landing pages success at all. The study justifies that it is not reasonable for a visitor to attract through means of an advertisement stating a specific offer or product and then surf the landing page to find that its headline is different. However, it is true that the first thing his eyes observe on the landing page is the same marketing message, which he saw, got his satisfaction, and affected him so that he surfed the landing page. Many lose thousands of dollars because of overlooking this point.

The study of Calvo (2017) confirms that statistics indicate that $80 \%$ of the success of a given advertisement and marketing message depends on the headline, where the site only has a few seconds to attract the attention of the visitor. A headline can be utilized to affect the visitor's perceptions. Many visitors make their decisions based on their feelings rather than logic.

The study of Rowley (2015) indicates that the marketing message should be attractive and use the suspense approach, and it should include numbers and evidence confirming the quality and effectiveness of the product provided. The study of Reyes (2016) concludes that the content of landing page is remarkably vital through providing a content enough for the visitor to feel secure in the purchase, providing the information necessary to complete the purchase. Besides urging to take action and the input form, there must be a good content that helps the visitor decide to buy and convert to be a buyer. The study adds that the content must be attractive and logical. The study of Jarvenpaa (2016) adds that the page should use strong headings, whether for the headlines or subheadings so that the visitor can quickly access the advantages of the product.

The study of Gregg (2018) suggests that an attractive video promoting the marketed service, one of the most advanced techniques of the landing page rather than the text content can be displayed. The study of Brynjolfsson (2016) reports that the provided content should be consistent with the visitor's expectations, in addition to being simple, clear, and concise to the visitor. The confusing page causes the site to lose its visitors. The study adds that a presentation, which is easier to read, including the advantages and benefits of the product and how to benefit from it must be written, and not just a list of features.

The studies of Chen (2015) and Huizingh (2015) suggest that there must be an urging phrase to take action, which is the central goal of converting visitors to the landing page. Therefore, the sole purpose of the conversion to the landing page should be to take action and not to distract the visitor with links leading to missing the visitor. The study of Gofman (2016) indicates that it is remarkably significant for the landing page to give the visitors trust, gained by displaying the perspectives of the product's experimenter. These perspectives show that other people benefited from their use of the product will support its quality, such as the customers' testimonials. These testimonials from customers satisfied with the product help more than approach the visitor. A landing page must contain a space to display the perspectives of the buyers experiencing the product. These perspectives can initially be obtained from friends and then from the buyers who already purchased.

The study of Figueiredo (2017) agrees with the previous studies in the significance of granting trust for the visitors. The study implies that the more the site is capable of convincing the buyers who already judged the product to demonstrate their positive experience of the product, the higher the conversion rate that the product will receive. The study of Fogg (2016) emphasizes the significance of placing the urging button to take action in the appropriate position and not at the end of the landing page. The visitor may log out of the page before he or she reaches it. Visitors do not then read everything. Not only can that, but the color of the action button motivate the visitor to take action. 
The study of Gefen (2017) implies that the landing page should include ideal design principles, such as contrast, white space, color selection as well as the position and color of the urging button to take action. Moreover, the page should be attention to the design of the form through which the visitor is required to provide information and data to contact and strengthen the relationship. This information must be correctly designed, the visitor should not be required for not used information and the site does not need.

The study of Geissler (2016) adds that a design responsive with cell phones must be developed as they are now used extensively to access the internet. The study also suggests that the page code should not be confused as the error in the page code has a negative impact on the download speed. The page should be simple in design to be fast loaded. The studies of Gao (2015) and Lucian (2014) recommends the participation of visitors through social networks. The existence of followers of the landing page via social media leads to see the page content from a much larger number. Whether or not a visitor buys, the site must be in touch with them via social networks. Through these networks, marketing message and news, experiences, product presentations, free lessons, gifts, and etc. can be sent. A button for each social media must also be created. The primary goal of these followers is always to convert the visitor into a customer.

Brief of Literature: The previous studies indicated that they are modern due to the novelty of the topic. They do not even directly discuss the landing pages, but they discussed other topics and assumed some results of the landing pages by addressing the topics representing the focus of interest of the landing pages. Thus, there is a severe lack of previous studies on this aspect. The studies did not address the topic of landing pages and their role in increasing conversion rates separately. The researcher did not find any Arab study addressing the subject, even as a minor subject, as appeared in foreign studies. Therefore, the current study will address this severe lack of the previous studies.

\section{Research Questions}

It is noticed that conversion rates across Saudi electronic marketing sites has a sharp drop. The rate does not exceed $0.5 \%$, which is a very low rate as the global rate reaches $8 \%$ : $10 \%$. The reason for this is the lack of interest in Saudi e-shopping sites with the latest tools that attract visitors to them and urges them to purchase, such as the landing page, which has recently become (especially the last two years) the most important and the best tools ever. It also increases the effectiveness of electronic marketing as it increases the visitors' conversion rates. Saudi electronic marketing sites are noted to be ineffective and not attracting visitors. When visitors access to these sites, they do not urge them to continue with the purchase, but as soon as the visitor access to the page, he does not stay there and leaves immediately without purchasing.

The problem here is the lack of knowledge of the Saudi electronic marketing site with the modern tools of electronic marketing, which contribute to increase the conversion rates, meaning that buying from the site. Landing pages are the latest electronic marketing tool, which increases the effectiveness of sites and motivates purchasing from it. Most sites do not have any knowledge about what a landing page is and may not set it up despite its significance to conversion rates. It is, therefore, necessary to identify the current situation of landing pages in Saudi websites and also identify the optimal form of these pages. And then identify the extent of to which the Saudi websites are committed to offering a landing page that increases their conversion rates. Thus, either they would increase sales and profits or not. The study problem is, therefore, the following question: "Do professional landing pages in Saudi electronic marketing sites increase conversion rates?"

\section{This question is divided into several sub-questions}

RQ1: Do professional landing pages have a significant role in increasing conversion rates of electronic marketing sites?

RQ2: Does the marketing message of the landing page contribute to increasing conversion rates of Saudi electronic marketing sites?

RQ3: Does a persuasive content of landing pages consider a factor in increasing the conversion rates of Saudi electronic marketing sites?

RQ4: Does granting trust for the visitors of landing pages increase conversion rates of Saudi electronic marketing sites?

RQ5: Do the sound design and page programming of landing pages lead to increase the conversion rates of Saudi electronic marketing sites? 
RQ6: Does visitors' participation via social media in landing pages contribute to increasing the conversion rates of Saudi electronic marketing sites?

\section{Hypotheses}

The study of Smith (2017) suggests that the professional landing pages have a significant impact on increasing the conversion rates of e-shopping sites. It is a modern tool of electronic marketing, proving to be interactive in urging visitors to convert from a mere visitor to the page to a customer who purchases from the site. Thus, the first hypothesis can be formulated as follows:

\section{The First Hypothesis:}

There would be no statistically significant relationship between the creation of professional landing pages and the contribution to increasing the conversion rates of the Saudi electronic marketing websites. The study of Pour (2016) indicates that there is a remarkable impact to follow specific criteria for creating professional landing pages that support the sites to increase the conversion rates and then sales and profits. Accordingly, the following hypothesis should be formulated:

\section{The Second Hypothesis:}

There would be no statistically significant relationship between the creation criteria of professional landing pages and the contribution to increasing the conversion rates of the Saudi electronic marketing websites. The study of Jennings (2015) indicates that the content submitted on landing pages has a significant impact on making the landing page more influential and attractive to the visitors. Therefore, if the sites give due attention to this content and provide the visitor with all significant information, which helps him make the purchase decision, a large number of visitors will approve that, which will contribute to their conversion to be customers. Accordingly, the sub-hypothesis I of the second hypothesis is:

\section{The Sub-Hypothesis I of the Second Hypothesis:}

There would be no statistically significant relationship between the content provided in professional landing pages and the contribution to increasing the conversion rates of the Saudi electronic marketing websites. The study of Soohoo (2017) suggests that as the content has a remarkable impact on attracting and urging visitors to take action, as does granting trust for visitors. It is necessary to grant them trust in the product from the presentation of the experiences of those who have already purchased the product, as well as the display of experts' opinions. Accordingly, the sub-hypothesis II of the second hypothesis is formulated:

The Sub-Hypothesis II of the Second Hypothesis:

There would be no statistically significant relationship between granting trust for the visitors of the professional landing pages and the contribution to increasing the conversion rates of the Saudi electronic marketing websites. The study of Braun (2016) suggests that the design and programming of landing pages play a remarkable significant role in the process of attracting and urging visitors to convert to customers by taking specific action. For example, the positions and colors of buttons that remarkably urge the visitor to take action must be carried out according to the criteria that work on this urge. Accordingly, the sub-hypothesis III of the second hypothesis is:

\section{The Sub-Hypothesis III of the Second Hypothesis:}

There would be no statistically significant relationship between the design and programming of professional landing pages and the contribution to increasing the conversion rates of the Saudi electronic marketing websites. The study of Shang (2017) indicates that social networking sites have captured an extremely high interest from consumers. They have become necessary for e-shopping, especially for the young generation, who mostly depends on them and trust them a lot. Shopping experts always advise to utilize these sites and connect them to shopping sites, especially landing pages, which are extremely helpful in urging the visitors to purchase and convert them into customers. Therefore, the sub-hypothesis IV of the Second hypothesis is formulated:

The Sub-Hypothesis IV of the Second Hypothesis:

There would be no statistically significant relationship between the participation of visitors via social media in professional landing pages and the contribution to increasing the conversion rates of the Saudi electronic marketing websites. 
The study of Gafni (2016) indicates that different marketing message inconsistent with the product advertisements will be extremely averse to the visitors, who will soon log off the site if they do not perceive that the marketing message matches the advertisements they saw about the product. Accordingly, the sub-hypothesis V of the second hypothesis is:

\section{The Sub-Hypothesis $V$ of the Second Hypothesis:}

There would be no statistically significant relationship between the marketing message of professional landing pages and the contribution to increasing the conversion rates of the Saudi electronic marketing websites.

\section{The Significance}

The study significance is due to its scientific and practical importance.

\section{7-1 The Scientific Significance:}

The scientific significance of the study stems from the modernity of the subject and the severe scarcity of research, foreign or Arabic, especially Arabic. The researcher did not find any Arab study that addressed this vital subject. However, this study is the first Arab studies that addressed the subject.

\section{7-2 The Practical Significance:}

The practical significance of the study is due to the importance of electronic marketing, becoming the center of interest of all companies. It has recently become the standard marketing tool for many products and will be soon a unique tool. Consequently, there is an increasing interest in the means and tools helping optimize its use. One of these remarkable modern tools is the landing pages, which consider a tool to increase the conversion rates in the site and then convert the visitor into a customer.

The scientific significance of the study stems from the necessity to identify the professional form of landing pages, which can help Saudi electronic marketing sites to increase the conversion rates and thus increase sales and profits. Saudi electronic marketing sites lack the tools that settle and increase the results desired from electronic marketing. Most of them are advertisement sites that are not effective at all.

\section{Methodology}

\section{6-1 The Method Used}

The study is based on the analytical descriptive approach. Through this approach, the previous studies related to our study subject were identified. The uncovered points in them are treated and then the hypotheses identified and the raw data collected through the distribution of a questionnaire on the study units to verify the validity or invalidity of the hypotheses and to conclude the results and recommendations of the study.

\section{6-2 The Study Population:}

The study population consists of two groups:

A. The first group: All consumers who do e-shopping in Saudi Arabia.

B. The second group: Experts and specialists in this field.

\section{6-3 The Study Sample:}

The study sample consisted of two groups:

A. First Group: A sample of consumers who conduct electronic marketing online. An electronic form was distributed. The sample size was determined as follows:

Due to the inability to identify the number of the Saudi population who are doing electronic shopping, the population, in this case, becomes unknown size. Thus, the equation of determining the appropriate sample size in an unknown population is:

$\mathrm{N}=\frac{\mathrm{Z}^{2}}{\mathrm{SE}^{2}} \times \mathrm{f}(1-\mathrm{f})$

Where:

$\mathrm{N}$ : sample size

$\mathrm{Z}$ : the standard value at a certain confidence interval is 1.96 at a significance level of 0.05 .

SE: the standard error allowed here is 0.05 at a confidence interval of $95 \%$.

$\mathrm{F}$ : the degree of variance among the units of the statistical population and the scientists regularly called it to be 0.5 . 
Therefore, sample size is:

$\mathrm{N}=\frac{(1.96)^{2}}{(0.05)^{2}} \times 0.5(1-0.5)=384$

B. Second Group: A sample of experts and specialists in this field. The sample size of this group was 47 units. Thus, the sample size of the first group (consumers) is 384 units. The sample size of the second group (experts and specialists) is 37 units.

\section{6-4 The Type and Sources of Data Collection:}

Two types of data were used:

A. The Secondary data: The study relied on research, books, and references that addressed this subject to create a reliable theoretical framework on the subject of the research.

B. The Raw Data: The study relied on distributing a questionnaire to the research units. An electronic questionnaire was distributed via the websites to the study sample. Its purpose was to identify the impact of landing pages on their conversion rates, as well as recognizing the extent to which professional landing pages are used in Saudi websites and how each element of the professional landing page affects their conversion rates.

\section{6-5 Measurements Used to Measure the Variables:}

Five-Point Likert Scale was used to measure the views of the sample units on the variables of the study, consisting of 5 degrees (where number 5 indicates Strongly Agree and the scale is 0 and Strongly Disagree). A set of statements was used to independently measure each variable obtained from previous studies.

\section{6-6 The Methods of Data Analysis:}

The used statistical methods included some descriptive statistical analysis and the statistical methods associated with the program (SPSS).

7. Results: Some statistical methods were used in (SPSS).

\section{7-1 Validity and Reliability Indicators:}

7-1-1 Measurement Tool Validity: It means the research accuracy in measuring the purpose for which it was designed. For this purpose, the questionnaire was introduced to a number of professors in the field of marketing. The amendments they made to the questionnaire were made.

Measurement Tool Reliability: It means the possibility of obtaining valid and reliable results when used in scientific research. To ensure the tool reliability, the analysis of Alpha Cronbach was used. It means the approval of the question's statements, which exceeds 60\%. The results are as indicated As in Table (1) of the Appendixes.

Table (1) indicating Alpha Cronbach Analysis to test the reliability of the measurement tool

\begin{tabular}{|c|c|c|}
\hline Question Aspect & $\begin{array}{l}\text { Number of } \\
\text { paragraphs }\end{array}$ & Alpha Cronbach \\
\hline Create professional landing pages & 15 & $87 \%$ \\
\hline Grant trust for professional landing page visitors & 6 & $79 \%$ \\
\hline $\begin{array}{l}\text { Participation of visitors via social media in professional } \\
\text { landing pages }\end{array}$ & 5 & $81 \%$ \\
\hline Marketing message of professional landing pages & 14 & $83 \%$ \\
\hline Design and program professional landing pages & 11 & $73 \%$ \\
\hline Content provided in professional landing pages & 12 & $84 \%$ \\
\hline
\end{tabular}

\section{7-2 The Descriptive Analysis of Data:}

The results of the descriptive analysis show that $95 \%$ of the respondents visit the online purchasing sites. $82 \%$ of respondents certainly take action through the purchase sites (where they buy or register in the mailing lists according to the procedure required from the site). Only 3\% also buys from Saudi shopping malls, which represents a small percentage that does not meet the Saudi government's interest in e-commerce and overcoming all obstacles to it. This percentage indicates that there are problems in these sites, one of which we will identify in this study.

\section{7-3 Analyzing the Results of Testing Hypotheses :}




\section{The First Hypothesis}

There would be no statistically significant relationship between the creation of professional landing pages and the contribution to increasing the conversion rates of the Saudi electronic marketing websites. To test this hypothesis, simple correlation analysis was used, As shown in Table (2) of the Appendixes. It is clear from the view of the consumers' sample from Table (2) in the Appendixes. that there is a strong correlation between the creation of professional landing pages and the contribution to increasing the conversion rates of the Saudi electronic marketing sites. It is illustrated by the high correlation coefficient $(94 \%)$.

Table (2) Results of correlation and regression analysis of the first hypothesis

\begin{tabular}{lllllll}
\hline \multirow{2}{*}{ Sample } & \multirow{2}{*}{$\mathbf{2}$} & \multirow{2}{*}{$\mathbf{R}^{\mathbf{2}}$} & $\mathbf{F}$ & \multicolumn{3}{l}{$\mathbf{T}$} \\
\cline { 4 - 7 } & & & Calculated F & Sing F & Calculated T & Sing T \\
\hline Consumers & 0.943 & 0.881 & 0.000 & 44.369 & 61.245 & 0.016 \\
\hline Experts & 0.903 & 0.815 & 0.000 & 35.961 & 56.125 & 0.021 \\
\hline
\end{tabular}

The results also indicate that the independent variable explains approximately $88 \%$ of the change in the dependent variable. The remaining percentage is due to other independent variables and random error. The results show a high value of calculated $\mathrm{F}$ from the tabulated $\mathrm{F}$, which means that there is a significant relationship between the dependent variable and the independent variable. It is also clear that the model is significant in the significance of $\mathrm{T}$. Thus, null hypothesis is rejected and the alternative hypothesis is accepted. It is also clear from the results of the previous table and through the opinions of the experts that there is a strong correlation between the creation of professional landing pages and the contribution to increasing the conversion rates of Saudi electronic marketing sites, where the correlation coefficient value is $90 \%$. It is also clear that the independent variable explains approximately $82 \%$ of the change in the dependent variable. The remaining percentage is due to other independent variables and random error. The results $\mathrm{sh} w$ a high value of calculated $\mathrm{F}$ from the tabulated $\mathrm{F}$, which means that there is a significant relationship between the dependent variable and the independent variable. It is also clear that the model is significant in the significance of T. Thus, null hypothesis is rejected and the alternative hypothesis is accepted. As for the extent of the difference between the opinion of the sample of consumers and the sample of experts, the study relied on t test. The results shown in Table (3) of the Appendixes. indicated that there is no difference between the opinions of the two samples on the importance of creating professional landing pages to contribute to increasing the conversion rates as the level of significance is $t>0.05$.

Table (3) Results of t-test to test the difference between the mean of the two samples of the first hypothesis

\begin{tabular}{lllll}
\hline Sample & M & SD & t test & Sig. \\
\hline Consumers & 3.24 & 0.420 & t Value & 0.916 \\
\hline Experts & 3.12 & 0.411 & 0.842 & 0.916 \\
\hline
\end{tabular}

The Second Hypothesis:

There would be no statistically significant relationship between the creation criteria of professional landing pages and the contribution to increasing the conversion rates of the Saudi electronic marketing websites. Multiple regression analysis was used to verify the validity or invalidity of the hypothesis, and its results are shown in Table (4) of the Appendixes. The previous table indicates, through the opinions of the consumer sample, that there is a very strong correlation between the dependent variable and the independent variable where $\mathrm{R}$-value is about $86 \%$.

Table (4) shows the multiple regression analysis of the second hypothesis- consolidated

\begin{tabular}{llllllll}
\hline Sample & \multirow{2}{*}{} & \multirow{2}{*}{$\mathbf{R}^{2}$} & Beta & $\begin{array}{l}\text { F } \\
\text { Calculated }\end{array}$ & $\begin{array}{l}\text { Sing } \\
\mathbf{F}\end{array}$ & $\begin{array}{l}\text { Calculated } \\
\mathbf{T}\end{array}$ & $\begin{array}{l}\text { Sing } \\
\mathbf{T}\end{array}$ \\
\hline Consumers & 0.856 & 0.727 & 2.89 & 286.365 & 0.000 & 87.652 & 0.009 \\
\hline Experts & 0.814 & 0.697 & 2.05 & 198.781 & 0.000 & 80.984 & 0.011 \\
\hline
\end{tabular}

The results of $\mathrm{R}^{2}$ also show that $73 \%$ of the change in the dependent variable is due to the change in the independent variable. The remaining percentage is due to other factors. The previous table and the calculated $\mathrm{F}$ value illustrate that there is a significant relationship between the dependent variable and the independent variable where it exceeds its tabulated value. It is also clear that the model is significant in the significance of T. Thus, null hypothesis is rejected and the alternative hypothesis is accepted. 
The opinion of the experts' sample indicates that there is a remarkably strong correlation between the dependent variable and the independent variable, which is demonstrated by $\mathrm{R}$-value being about $81 \%$. The results of $\mathrm{R}^{2}$ also show that $70 \%$ of the change in the dependent variable is due to the change in the independent variable. The remaining percentage is due to other factors. The results also illustrate through the calculated $\mathrm{F}$ value that there is a significant relationship between the dependent variable and the independent variable where it exceeds its tabulated value. It is also clear that the model is significant in the significance of $\mathrm{T}$ whose value is more than the tabulated value. Thus, null hypothesis is rejected and the alternative hypothesis is accepted.

As for the extent of agreement or disagreement between the opinion of the consumers sample and the experts sample on this hypothesis, t-test indicated, As shown in Table (5) of the Appendixes. that there is no difference between the opinions of two samples on the existence of a correlation between the criteria of the creation of professional landing pages and the contribution to increasing the conversion rates of Saudi electronic marketing sites. The level of significance is $>0.05$.

Table (5) Results of t-test to test the difference between the mean of the two samples of the second hypothesis - consolidated

\begin{tabular}{|l|l|l|l|l|}
\hline Sample & \multirow{2}{*}{ M } & SD & t test & \\
\cline { 4 - 5 } & & & T & Sig. \\
\hline Consumers & 3.01 & 0.493 & 1.262 & 0.235 \\
\hline Experts & 2.98 & 0.452 & & \\
\hline
\end{tabular}

Sub-Hypothesis I of the Second Hypothesis:

There would be no statistically significant relationship between the content provided in professional landing pages and the contribution to increasing the conversion rates of the Saudi electronic marketing websites. The study relied on the multiple regression analysis to verify the validity or invalidity of the study, As shown in Table (6) of the Appendixes.

Table (6) indicating the multiple regression analysis of the sub-hypothesis I of the second hypothesis

\begin{tabular}{|c|c|c|c|c|c|c|c|}
\hline \multirow[b]{2}{*}{ Sample } & \multirow[b]{2}{*}{$\mathbf{R}$} & \multirow[b]{2}{*}{$\mathbf{R}^{2}$} & \multirow[b]{2}{*}{ Beta } & \multicolumn{2}{|l|}{$\mathbf{F}$} & \multicolumn{2}{|l|}{$\mathbf{T}$} \\
\hline & & & & $\begin{array}{l}\text { Calculated } \\
\text { F }\end{array}$ & $\begin{array}{l}\text { Sing } \\
\text { F }\end{array}$ & $\begin{array}{l}\text { Calculated } \\
\text { T }\end{array}$ & $\begin{array}{l}\text { Sing } \\
T\end{array}$ \\
\hline Consumers & 0.901 & 0.842 & 1.67 & 194.238 & 0.000 & 79.21 & 0.017 \\
\hline Experts & 0.920 & 0.863 & 1.96 & 188.361 & 0.000 & 62.37 & 0.006 \\
\hline
\end{tabular}

The opinion of consumers' sample of the results of the previous table shows that there is a remarkably strong correlation between the dependent variable and the independent variable indicated by R-value of $90 \%$. $\mathrm{R}^{2}$ also shows that $84 \%$ of the change in the dependent variable is due to the change in the independent variable. The remaining percentage is due to other factors. The results of the table also indicated that the calculated $\mathrm{F}$ value is greater than its tabulated value, indicating that there is a significant relationship between the dependent variable and the independent variable. The model is also significant of $\mathrm{T}$ significance. Thus, null hypothesis is rejected and the alternative hypothesis is accepted. The opinion of the experts' sample indicates that there is a remarkably strong correlation between the dependent variable and the independent variable, where $\mathrm{R}$-value is about $92 \%$. $\mathrm{R}^{2}$ value shows that $86 \%$ of the change in the dependent variable is due to the change in the independent variable. The remaining percentage is due to other factors. The results also show that the calculated $F$ value is grater that the tabulated $\mathrm{F}$ value, which means that there is a significant relationship between the dependent variable and the independent variable. The calculated $\mathrm{T}$ value is greater than the tabulated $\mathrm{T}$ value, which means that the relation is significant. Thus, null hypothesis is rejected and the alternative hypothesis is accepted.

Table (7) Results of t-test to test the difference between the mean of the two samples of the second hypothesis - consolidated

\begin{tabular}{lllll}
\hline Sample & M & SD & t test & Sig. \\
\hline Consumers & 4.56 & 0.513 & T & 0.594 \\
\hline Experts & 4.18 & 0.508 & 0.952 & 0.59 \\
\hline
\end{tabular}

T test is used As shown in Table (7) of the Appendixes to determine if there is a difference between the opinion of the consumers' sample and the experts' sample. 
The results of the test indicated that there is no difference between the opinions of the two samples on the correlation between the content presented in the professional landing pages and the contribution to increasing the conversion rates of the Saudi electronic marketing sites, where the level of significance is $>0.05$.

\section{Sub-Hypothesis II of the Second Hypothesis:}

There would be no statistically significant relationship between granting trust for the visitors of the professional landing pages and the contribution to increasing the conversion rates of the Saudi electronic marketing websites. To verify the validity or invalidity of the study, the study was based on multiple regression analysis, As shown in Table (8) of the Appendixes. The previous results indicate, through the opinions of the consumers' sample, that there would be a remarkably strong correlation between the dependent variable and the independent variable where R-value is about $80 \%$.

Table (8) shows the multiple regression analysis of the sub-hypothesis II of the second hypothesis

\begin{tabular}{|c|c|c|c|c|c|c|c|}
\hline \multirow[b]{2}{*}{ Sample } & \multirow[b]{2}{*}{$\mathbf{R}$} & \multirow[b]{2}{*}{$\mathbf{R}^{2}$} & \multirow[b]{2}{*}{ Beta } & \multicolumn{2}{|l|}{$\mathbf{F}$} & \multicolumn{2}{|l|}{$\mathbf{T}$} \\
\hline & & & & $\begin{array}{l}\text { Calculated } \\
\text { F }\end{array}$ & $\begin{array}{l}\text { Sing } \\
\text { F }\end{array}$ & $\begin{array}{l}\text { Calculated } \\
\mathbf{T}\end{array}$ & $\begin{array}{l}\text { Sing } \\
\mathbf{T}\end{array}$ \\
\hline Consumers & 0.795 & 0.701 & 1.67 & 194.238 & 0.000 & 79.21 & 0.017 \\
\hline Experts & 0.823 & 0.786 & 1.94 & 213.014 & 0.000 & 85.36 & 0.012 \\
\hline
\end{tabular}

The ratio of $\mathrm{R}^{2}$ also shows that $70 \%$ of the change in the dependent variable is due to the change in the independent variable. The remaining percentage is due to other factors. The value of calculated $\mathrm{F}$, which exceeds its tabulated value, indicates that there is a significant relationship between the dependent variable and the independent variable. The calculated $\mathrm{T}$ value, which exceeds its tabulated value, indicates that the relationship is significant. Thus, null hypothesis is rejected and the alternative hypothesis is accepted. The experts' opinion indicates that there is a remarkably strong correlation between the dependent variable and the independent variable, where $\mathrm{R}$-value is $82 \%$. The ratio of $\mathrm{R}^{2}$ also shows that $79 \%$ of the change in the dependent variable is due to the change in the independent variable. The remaining percentage is due to other factors. The value of calculated F, which exceeds its tabulated value, indicates that there is a significant relationship between the dependent variable and the independent variable. The calculated $T$ value, which exceeds its tabulated value, indicates that the relationship is significant. Thus, null hypothesis is rejected and the alternative hypothesis is accepted. To determine the extent of the difference between the opinion of the consumers' sample and the experts' sample, $t$ test result indicates that there is an agreement of the two samples on the existence of a strong relationship between granting trust for the visitors of the professional landing pages and the contribution to increasing the conversion rates of Saudi electronic marketing sites As shown in Table (9) of the Appendixes The level of significance is $t>0.05$.

Table (9) Results of t-test to test the difference between the mean of the two samples of the second hypothesis - consolidated

\begin{tabular}{lllll}
\hline Sample & M & SD & t test & \\
\cline { 5 - 5 } Consumers & 2.64 & 0.341 & T & Sig. \\
\hline Experts & 2.58 & 0.319 & 0.756 & \multirow{2}{*}{0.618} \\
\hline
\end{tabular}

Sub-Hypothesis III of the Second Hypothesis:

There would be no statistically significant relationship between the design and programming of professional landing pages and the contribution to increasing the conversion rates of the Saudi electronic marketing websites. The study relied on the multiple regression analysis to verify the validity or invalidity of the study, As shown in Table (10) of the Appendixes. The results of the previous table indicate that the consumers' sample implies that there is a very strong correlation between the dependent variable and the independent variable where R-value is $89 \%$. $\mathrm{R}^{2}$ means that $87 \%$ of the change in the dependent variable is due to the change in the independent variable. The remaining percentage is due to other factors. The value of calculated $\mathrm{F}$, which exceeds its tabulated value, indicates that there is a significant relationship between the dependent variable and the independent variable.

It is also clear that the calculated $\mathrm{T}$ value exceeds its tabulated value, indicating that the relationship is significant. Thus, null hypothesis is rejected and the alternative hypothesis is accepted. 
Table (10) indicating the multiple regression analysis of the sub-hypothesis III of the second hypothesis

\begin{tabular}{|c|c|c|c|c|c|c|c|}
\hline \multirow[b]{2}{*}{ Sample } & \multirow[b]{2}{*}{$\mathbf{R}$} & \multirow[b]{2}{*}{$\mathbf{R}^{2}$} & \multirow[b]{2}{*}{ Beta } & \multicolumn{2}{|l|}{$\mathbf{F}$} & \multicolumn{2}{|l|}{$\mathbf{T}$} \\
\hline & & & & $\begin{array}{l}\text { Calculated } \\
\text { F }\end{array}$ & $\begin{array}{l}\text { Sing } \\
\mathbf{F}\end{array}$ & $\begin{array}{l}\text { Calculated } \\
\text { T }\end{array}$ & $\begin{array}{l}\text { Sing } \\
T\end{array}$ \\
\hline Consumers & 0.891 & 0.871 & 1.34 & 176.567 & 0.000 & 69.24 & 0.036 \\
\hline Experts & 0.823 & 0.783 & 1.03 & 155.369 & 0.000 & 59.34 & 0.041 \\
\hline
\end{tabular}

The experts' sample indicates that there is a remarkably strong correlation between the dependent variable and the independent variable, where $\mathrm{R}$-value is about $82 \%$. $\mathrm{R}^{2}$ means that $87 \%$ of the change in the dependent variable is due to the change in the independent variable. The remaining percentage is due to other factors. The value of calculated F, which exceeds its tabulated value, indicates that there is a significant relationship between the dependent variable and the independent variable. It is also clear that the calculated $\mathrm{T}$ value exceeds its tabulated value, indicating that the relationship is significant. Thus, null hypothesis is rejected and the alternative hypothesis is accepted.

Table (11) Results of t-test to test the difference between the mean of the two samples of the second hypothesis - consolidated

\begin{tabular}{|c|c|c|c|c|}
\hline \multirow{2}{*}{ Sample } & \multirow{2}{*}{$\mathbf{M}$} & \multirow{2}{*}{ SD } & \multicolumn{2}{|c|}{ t test } \\
\hline & & & $\mathbf{T}$ & Sig. \\
\hline Consumers & 4.01 & 0.319 & 006 & 0627 \\
\hline Experts & 3.84 & 0304 & 0.861 & 0.627 \\
\hline
\end{tabular}

The result of $\mathrm{t}$ test indicated that there is no difference between the opinions of the two samples on the existence of relationship between granting trust for the visitors of the professional landing pages and the contribution to increasing the conversion rates of Saudi electronic marketing sites. As shown in Table (11) in the Appendixes. Where the level of significance is $t>0.05$.

Sub-Hypothesis IV of the Second Hypothesis:

There would be no statistically significant relationship between the participation of visitors via social media in professional landing pages and the contribution to increasing the conversion rates of the Saudi electronic marketing websites. The study relied on the multiple regression analysis to verify the validity or invalidity of the study, As shown in Table (12) in the Appendixes. The previous table indicates, through the opinions of the consumers' sample, that there is a very strong correlation between the dependent variable and the independent variable where $\mathrm{R}$-value is $86 \% . \mathrm{R}^{2}$ also shows that $80 \%$ of the change in the dependent variable is due to the change in the independent variable. The remaining percentage is due to other factors. Because the value of calculated $\mathrm{F}$ exceeds its tabulated value, there is a significant relationship between the dependent variable and the independent variable. It is also clear that the calculated $\mathrm{T}$ value exceeds its tabulated value, indicating that the relationship is significant. Thus, null hypothesis is rejected and the alternative hypothesis is accepted.

Table (12) indicating the multiple regression analysis of the sub-hypothesis IV of the second hypothesis

\begin{tabular}{|c|c|c|c|c|c|c|c|}
\hline \multirow[b]{2}{*}{ Sample } & \multirow[b]{2}{*}{$\mathbf{R}$} & \multirow[b]{2}{*}{$\mathbf{R}^{2}$} & \multirow[b]{2}{*}{ Beta } & \multicolumn{2}{|l|}{$\mathbf{F}$} & \multicolumn{2}{|l|}{$\mathbf{T}$} \\
\hline & & & & $\begin{array}{l}\text { Calculated } \\
\text { F }\end{array}$ & $\begin{array}{l}\text { Sing } \\
\text { F }\end{array}$ & $\begin{array}{l}\text { Calculated } \\
\mathbf{T}\end{array}$ & $\begin{array}{l}\text { Sing } \\
\mathbf{T}\end{array}$ \\
\hline Consumers & 0.863 & 0.799 & 1.56 & 186.423 & 0.000 & 76.52 & 0.042 \\
\hline Experts & 0.882 & 0.813 & 1.23 & 164.192 & 0.000 & 81.06 & 0.035 \\
\hline
\end{tabular}

The opinion of the experts' sample indicates that there is a remarkably strong correlation between the dependent variable and the independent variable, where $\mathrm{R}$-value is $88 \% . \mathrm{R}^{2}$ value shows that $81 \%$ of the change in the dependent variable is due to the change in the independent variable. The remaining percentage is due to other factors. The value of calculated $\mathrm{F}$, which exceeds its tabulated value, indicates that there is a significant relationship between the dependent variable and the independent variable. It is also clear that the calculated $\mathrm{T}$ value, which exceeds its tabulated value, indicates that the relationship is significant. Thus, null hypothesis is rejected and the alternative hypothesis is accepted. The result of t-test, illustrated in Table (13) in the Appendixes, indicates that there is an agreement of the two samples on the existence of a strong relationship between the visitors' participation via social media in the professional landing pages and the contribution to increasing the conversion rates of Saudi electronic marketing sites, where the level of significance is $t>0.05$. 
Table (13) Results of t-test to test the difference between the mean of the two samples of the second hypothesis - consolidated

\begin{tabular}{lllll}
\hline Sample & M & SD & t test & \\
\cline { 5 - 5 } Consumers & 2.87 & 0.350 & T & Sig. \\
\hline Experts & 2.72 & 0.341 & 0.923 & 0.316 \\
\hline
\end{tabular}

\section{Sub-Hypothesis $V$ of the Second Hypothesis:}

There would be no statistically significant relationship between the marketing message of professional landing pages and the contribution to increasing the conversion rates of the Saudi electronic marketing websites. The study relied on the multiple regression analysis to verify the validity or invalidity of the study, As shown in Table (14) of the Appendixes. The table and the opinions of the consumers' sample indicate that there would be a remarkably strong correlation between the dependent variable and the independent variable as the correlation coefficient indicated $91 \%$. The value of $\mathrm{R}^{2}$ also indicates that the independent variable explains approximately $85 \%$ of the change in the dependent variable. The remaining percentage is due to other independent variables and random error. The value of calculated $\mathrm{F}$, which exceeds its tabulated value, indicates that there is a significant relationship between the dependent variable and the independent variable. The calculated $\mathrm{T}$ value is greater than its tabulated value, which means that the relation is significant. Thus, null hypothesis is rejected and the alternative hypothesis is accepted.

Table (14) indicating the multiple regression analysis of the sub-hypothesis $V$ of the second hypothesis

\begin{tabular}{|c|c|c|c|c|c|c|c|}
\hline \multirow[b]{2}{*}{ Sample } & \multirow[b]{2}{*}{$\mathbf{R}$} & \multirow[b]{2}{*}{$\mathbf{R}^{2}$} & \multirow[b]{2}{*}{ Beta } & \multicolumn{2}{|l|}{$\mathbf{F}$} & \multicolumn{2}{|l|}{$\mathbf{T}$} \\
\hline & & & & $\begin{array}{l}\text { Calculated } \\
\text { F }\end{array}$ & $\begin{array}{l}\text { Sing } \\
\text { F }\end{array}$ & $\begin{array}{l}\text { Calculated } \\
\mathbf{T}\end{array}$ & $\begin{array}{l}\text { Sing } \\
\mathbf{T}\end{array}$ \\
\hline Consumers & 0.912 & 0.853 & 1.96 & 201.325 & 0.000 & 82.34 & 0.009 \\
\hline Experts & 0.873 & 0.810 & 2.31 & 225.146 & 0.000 & 90.75 & 0.015 \\
\hline
\end{tabular}

The sample of experts in the table and through the value of $\mathrm{R}(87 \%)$ shows that there is a strong correlation between the dependent variable and the independent variable. The value of $\mathrm{R}^{2}$ also indicates that the independent variable explains approximately $85 \%$ of the change in the dependent variable. The remaining percentage is due to other independent variables and random error. The value of calculated $\mathrm{F}$, which exceeds its tabulated value, indicates that there is a significant relationship between the dependent variable and the independent variable. The calculated $\mathrm{T}$ value, which also exceeds its tabulated value, also indicates that the relationship is significant. Thus, null hypothesis is rejected and the alternative hypothesis is accepted.

Table (15) Results of t-test to test the difference between the mean of the two samples of the second hypothesis - consolidated

\begin{tabular}{lccccc}
\hline \multirow{2}{*}{ Sample } & M & SD & \multicolumn{2}{c}{ t test } \\
\cline { 1 - 2 } \cline { 5 - 6 } Consumers & 4.02 & 0.361 & & T & Sig. \\
\hline Experts & 3.84 & 0.357 & & & 0.616 \\
\hline
\end{tabular}

As for the extent of agreement or disagreement between the two samples of the study on this hypothesis, the results of $t$ test, illustrated in table (15) in the Appendixes, indicated that there is no difference between the opinions of the two samples on the existence of a strong relationship between the marketing message of professional landing pages and the contribution to increasing the conversion rates of the Saudi electronic marketing websites. The level of significance is $t>0.05$.

\section{Conclusions}

Through the conducted field study, the study concluded the following results:

1. The results of the research show that creating professional landing pages is very important and contributes significantly to more the conversion rates. The lack of the landing pages means that the consumer should see the product's advertisement and then take action to buy directly. This does not occur via the Internet because advertisement only is not sufficient; however, it should be a method of convincing, attracting, and urging the visitor after reading the advertisement to convert from just a visitor reading the advertisement to a customer 
purchasing the product. Without this urge, attraction and persuasion to the consumer, he will read the advertisement and then logs off the site without any use of the site. Then, the site would lose many expenses directed to attract the visitor to read the advertisement and click it, especially if it is accounted for the number of clicks and conversion. The study showed an agreement between the sample of consumers and the sample of experts on the importance of this. The results also indicated that Saudi websites lacked professional landing pages and that most Saudi websites do not have landing pages at all, which shows a significant impact on the low conversion rates of these websites.

2. The results showed a need to pay attention to the content of the professional landing pages. The results showed that strong content works to attract visitors and provide them with the necessary information, which is enough, sufficient, and concise, to complete the required action. The visitor does not read all the content, and therefore it is necessary to determine a short content that meets the purpose and does not lead to the dispersion of the visitor so as not to leave the page and exit it completely. It should also motivate the visitor to a specific procedure, which is often the purchase. The results also showed an agreement between the sample of consumers and the sample of experts on the importance of the strong content to contribute to the increase in conversion rates. The study showed an agreement between the sample of consumers and the sample of experts on the importance of this. The results showed that Saudi websites do not care about the content presented on the landing pages. The content is very inadequate and does not amount to providing information about an online product, and the consumer does not directly see it. The content must give all the information about the product and be presented in an attractive way to the consumer so that it helps in converting the visitor to perform the required action.

3. The results showed the importance of the design and programming of landing pages. The distinctive design works to attract the visitor, but also works to well organize the page, especially for the position of the action button. The results also showed that things might seem small, but they are very significant because they might convert the visitor into a customer and increase the conversion rates, such as the color and position of the action button and all other buttons. Continuing maintenance of the landing page is also essential and needs to be taken into consideration to attract visitors. However, Saudi websites do not have a good design for landing page at all, and have no knowledge of the importance of this design and its psychological impact on the visitor and urge him to go to the action button.

4. The results also showed how important to grant the visitor trust, which is very important for taking action and increasing conversion rates. Displaying consumers' experiences, displaying experts' opinions or even displaying to the top product users, for example, help considerably to contribute to increasing the conversion rates. As for Saudi websites, there is absolutely no displaying about the experiences of consumers or experts. Therefore, these websites lack the confidence needed to give trust for a skeptical visitor who needs a boost of confidence motivating him to click the purchasing button.

5. The results showed that the participation of the visitors through social networking sites on the landing page is one of the most important things that can help increase the conversion rates, whether for visitors, who have taken action, bought or even have not purchased. This communication leads to a kind of loyalty, attracts and urges the consumer to purchase. It is very essential to create a connection through the social networking sites that help the visitor access directly to the landing page where the advertisement of the product through social networking sites, because of the importance of social networking sites today in electronic marketing. However, the reality for Saudi websites is quite diverse as the product advertisements are already available via social media but have no links to the landing pages. This actually affects the conversion rates where advertisements are useless without the link to landing pages.

6. The study also showed the importance of the marketing message where the message should be an extension of the advertisement and complementary to it, as well as pursue the same approach of the advertisement and does not go beyond the context of the advertisement. The landing page headline, for example, must match the advertisement provided for the product and the page contains only one marketing message.

In order for the marketing message to be appropriate, it is important to recognize and comprehend the patterns of the customer to whom the sufficient message is submitted so as to match his character and desires. It is also necessary to be fully aware of the quality of the procedure desired by the website so that the message is compatible with this purpose. Therefore, the message should be written professionally. The study also demonstrated the agreement between the two study samples on the importance of marketing message and its compatibility. 
The study also showed that Saudi landing pages do not care about the marketing message or the best way to prepare it. However, if done, they are done in a random way. The page contains more than one message that disperses the visitor, making him not excited to complete the purchase and leaving without returning to the website.

\section{Recommendations}

From the presentation of the results of the study, the study recommends the following:

1. Saudi websites should give due attention to the landing pages and create professional landing pages because of its importance in attracting and urging the visitors to purchase from the Saudi websites.

2. Saudi websites should pay attention to creating good content for the landing page, and rely on the persuasive content that attracts visitors.

3. Saudi websites should link their landing pages to the social networking sites and communicate with all visitors, whether those who purchased or not to do so because of the importance and influence of this communication in attracting the visitor and making him take action desired by the site.

4. It is necessary to grant trust for the consumers by the site and the landing pages which are concerned about this task. It is also important to present the experiences of others who have made the actual purchase and how they benefited from the product as well as the names of the experimenters, especially if they were names of known persons or bodies; in addition to presenting the experts' view in the product.

5. Companies should pay attention to the marketing message in a big way because its compatibility works to attract the visitor to purchase and therefore it must correspond to the advertisement and the headline of the page and the page should not contain more than a message.

6. Companies should also design a good website that plays a psychologically important role in attracting the consumer to complete the purchase from the website. Attention should also be paid to produce suitable programming of the website either it is from a specialist or even from the owners of the site because of its prominent role in attracting visitors.

7. Companies should take care of these pages professionally and do not neglect them in their attempts to reduce costs.

8. Companies should delegate the work of the pages to specialists and not be negligent in their work through the website if they do not have the full knowledge of how to prepare it.

9. Those responsible for the development of e-commerce in Saudi Arabia should guide the small entrepreneurs towards the importance of professional landing pages, and they are now a necessity and not just something complementary to the websites.

10. The official authorities should support the Saudi websites in terms of financial, technical or consulting means so that they can meet competition or will not have a position in the e-commerce market forever.

\section{Limitations Future Studies}

13-1The limitations of the study are:

- Objective Limitations: Research focuses only on the study of landing pages as one of the most influential tools of electronic marketing.

- Time Limitations: The time limitations of the research are 2018.

13-2 Future Studies are

1. Landing page relationship to the primary results of search page.

2. Search engines relationship to the landing page.

\section{References}

Ash, Tim. Landing page optimization; (2016); The Definitive Guide to Testing and Tuning for Conversions; Sybex; 44(2), 3-25.

Bart Weller, Lori Calcott. (2017); The Definitive Guide to Google AdWords Create Versatile and Powerful Marketing and Advertising Campaigns; Apress;25(1),75-94.

Braun, M., Lee, C.; Urban, G., ; Hauser, J. R. (2017); Does matching website characteristics to cognitive styles increase online sales? ; European Journal of Information Systems; 12(3),521-542.

Brinker, Scott. ;(2015) Honest seduction: Using Post-Click Marketing to Turn Landing Pages Into Game Changer; Austin; 15(3), 77-101. 
Brynjolfsson, E., \& Smith, M. D. (2016); Frictionless commerce? A comparison of Internet and conventional retailers. Management Science, 46(4),563-585.

Chen, C. W.; Koufaris, M. ( 2015 ), The impact of decision support system features on user overconfidence and risky behavior. European Journal of Information Systems, 24(6), 607-623.

Figueiredo, F.; Almeida, J. M.; Benevenuto, F; Gummadi, K. P. (2017); Does content determine information popularity in social media? A case study of YouTube videos' content and their popularity. In Proceedings of the SIGCHI Conference on Human Factors in Computing Systems ; New York, NY, USA: ACM; 14(2),979-982.

Fogg, B. J.; Marshall, J.; Kameda, T.; Solomon, J.; Rangnekar, A., Boyd, J., (2016) Brown, B. Web credibility research: A method for online experiments and early study results. In CHI '01 Extended Abstracts on Human Factors in Computing Systems ; New York, NY, USA: ACM; ; 34(2), 562-585.

Frédéric Boniol,Virginie Wiels, Yamine Ait Ameur,Klaus-Dieter Schewe. (2014); ABZ The Landing Gear Case Study; Springer Cham Heidelberg New York Dordrecht London; 16(4), 45-68.

Gafni, R. ; Golan, O. T. (2016), The influence of negative consumer reviews in social networks. Online Journal of Applied Knowledge Management, 4(2), 44-58.

Gang Wang, David Felstead, Cormac Herley, Jack W,Stokes. (2017);Detecting Malicious Landing Pages in Malware Distribution Networks ; IEEE; 10( 3), 651-672.

Gao, J.; Zhang, C.; Wang, K.; Ba, S. (2015); Understanding online purchase decision making: The effects of unconscious thought, information quality, and information quantity. Decision Support Systems; 53 (4), $772-795$.

Gefen, D. (2017); E-commerce: The role of familiarity and trust. Omega, Journal of Consumer Marketing; 28( 6),725-737.

Geissler, G. L.; Zinkhan, G. M.; Watson, R. T. (2016);The influence of home page complexity on consumer attention, attitudes, and purchase intent. Journal of Advertising, 35( 2), 69-80.

Glaser, J D. (2014); Secure development for mobile apps : how to design and code secure mobile applications with PHP and JavaScript; Auerbach Publications; 12(2),121-147.

Gofman, A.; Moskowitz, H. R.; Mets, T. (2016) ; Integrating science into web design: consumer-driven web site optimization. Journal of Consumer Marketing, 26(4), 286-298.

Gregg, D. G.; Walczak, S. (2018);Dressing your online auction business for success: An experiment comparing two eBay businesses. MIS Quarterly, 32(3), 653-670.

Harwood, Martin. (2015); Landing Page Optimization, For Dummies; Online Information Review;45(3) 22-47.

Huizingh, E. K. R. E. (2016); The content and design of web sites: An empirical study. Journal of Information \& Management, 37(3),123-134.

Invernizzi, S. Benvenuti, P. M. Comparetti, M. Cova, C. Kruegel, and G. Vigna. (2016); Evilseed: A guided approach to finding malicious web pages; in Proc. IEEE Symposium on Security and Privacy; 7(1) , 2149.

Jarvenpaa, S. L.; Tractinsky, N., ; Saarinen, L. (2016); Consumer trust in an internet store: A cross-cultural validation. Journal of Computer-Mediated Communication; 5(2), 125-162.

Jennings, Calvo. (2017); Google Inside AdWords: Go beyond the click with the "Landing pages" ; Online Journal of Applied Knowledge Management,. 6(4), 221-254.

Jennings, M. (2015); Theory and models for creating engaging and immersive ecommerce websites. In Proceedings of the 2015 ACM SIGCPR conference on Computer Personnel Research ACM; 21(2), 7785.

Jose Molina; Castillo, F.; Lopez-Nicolas, C.; Colomo-Palacios, R. Smith; (2017); The effect of information overload and disorganisation on intention to purchase online: The role of perceived risk and internet experience. Online Information Review; 38(4), 543-561.

Juan-Francisco Reyes; (2016); Effect of Emotion on Marketing Landing Page Conversion; In Partial Fulfillment to the Requirements for the Degree of Master of Science; ProQuest LLC; 23(3),368-392.

Linda Newman Lior. (2016); Writing for interaction : crafting the information experience for Web and software Apps; Elsevier Inc ; 17(2), 457-481.

Lucian, R. (2014); Digital overload: The effects of the large amounts of information when purchasing online. Journal of Internet Banking and Commerce, 19(2),452- 479.

Page, Rich. (2016); Website Optimization: An Hour a Day; Sybex; 44(3),78-94. 
Paulo Salem. (2017); User Interface Optimization using Genetic Programming with an Application to Landing Pages; Proc. ACM Hum.-Comput. Interact., 5(1),124-156.

Rowley, J. (2015); Understanding digital content marketing. Journal of Marketing Management; 24(5-6),517540.

Shang, R. A., \& Kao, C. Y. Chen, Y. C. ( 2017); The effects of information overload on consumers' subjective state towards buying decision in the internet shopping environment. Electronic Commerce Research and Applications, 8(1),48-58.

Smith, A., \& Anderson, M.(2016); Online shopping and e-commerce; Journal of Marketing Management, 14(16), $429-452$.

Smith, Pour. (2016);Marketing Experiments Blog: Customer-centric Marketing: 3 landing page pitfalls to avoid; Journal of Marketing Management 9(2),165-196

Soohoo, C.; Danielson, D.; Marable, L.; Stanford, J., ; Tauber, E. R; Fogg, B. J. (2017); How do people evaluate a web site's credibility. Persuasive Technology Lab: Stanford University; 18(4),664-687. 